reaction-rates, and to the principles underlying the elucidation of mechanism : later chapters are more specialized and refer to gas-phase reactions, liquidphase reactions (and homogeneous catalysis), polymerization and polymer reactions, biological reactions, and very fast reactions. Heterogeneous reactions, heterogeneous catalysis and other bi-phase processes are not treated.

Viewed as a whole this is unquestionably a useful source-book for chemists whose interests lie within or on the fringe of the field of reaction mechanism. The least successful aspects are the purely theoretical parts, for the absolute rate theory which is the natural foundation of the main sections of the book is very summarily presented, the degree of condensation being such that in some respects the foundation is insecure. For example, in the discussion of the effect of isotopic substitution (p. 26) it is claimed that, a $\mathrm{C}-\mathrm{H}$ bond being replaced by $\mathrm{C}-\mathrm{D}$, the maximum theoretical ratio of rate constants is $4 \cdot 3$. Actually, the author has calculated (approximately) the 'maximum' velocity ratio for a special, and certainly very rare, case in which the deformation vibrations have the same frequency in the ground and transition states; but none of this is explained. Probably no one will be misled, but it is disturbing to find several references to this 'derivation' at points later in the book.

The field covered in this volume is broad and correspondingly difficult to survey; but the authors have maintained in general a very even and interesting level. In a treatise on the methods of organic chemistry it is natural that liquid systems receive the most attention; but not the least useful sections are devoted to the theory and practice of relatively specialized techniques : for example, flow methods, which are becoming increasingly popular. It may, perhaps, be regretted that the section on rapid reactions is restricted to biochemical systems or to systems primarily of biochemical interest : no account is given of the investigation by ultrasonic and other new methods of simple, very fast reactions in the gas phase.

Binding and presentation conform to the high standard of the series, and a cumulative index to the earlier volumes is provided. J. C. D. BRAND

\section{RUSSIAN PROGRESS IN ELECTRON DIFFRACTION}

Electron Diffraction

By Prof. Z. G. Pinsker. Translated by J. A. Spink and E. Feigl. Pp. xiv $+443+25$ plates. (London: Butterworths Scientific Publications, Ltd., 1953.) 63s. net.

THE appearance of a translation of this important Russian book is very welcome. A specially contributed preface by the author suggests that Russian scientists are anxious for international co-operation, and this would be greatly helped by the appearance of further translations of this kind.

As an orthodox work on the theory and practice of electron diffraction, the book is very good; it deals with the elements of wave theory, the diffraction of waves by crystals, experimental methods, appara. tus, and practical results. The chapters on the last subject appear to deal fairly with Russian and non-Russian contributions, and it is evident that, in some types of electron-diffraction work, the Russians are well ahead. This is particularly true of crystalstructure determination ; since electrons are scattered by the field within an atom and not by electron density, hydrogen atoms are more easily detected by electrons than by X-rays, and work on this subject has been appearing in the Russian literature since 1948. As far as the reviewer is aware, the earliest comparable work in English is that of Cowley in Australia, published in 1953.

As a historical commentary, however, the book has several defects. For example, the discovery of electron diffraction is attributed solely to Davisson and Germer, Thomson's work being referred to, only incidentally, several pages later. Quite naturally, Russian work receives predominant attention; but it comes as a shock to find W. L. Bragg given only minor honours for what is usually known as Bragg's law; Prof. Pinsker consistently refers to this law as the Wulff-Bragg law, claiming that it was discovered by "the Russian scientist Wulff (Phys. Z., 14, 217 ; 1913) and simultaneously Bragg (Proc. Camb. Phil: Soc., 17, 43 ; 1912)".

This claim deserves some attention, since simultaneity can be claimed only if the later paper were received before the earlier one was published. In this instance, this is not so; Bragg's paper was published in November 1912, and Wulff's was not received until February 1913. Moreover, Wulff's idea arose out of a note published by Bragg in Nature, in December 1912, to which Wulff refers in his paper. Thus the claim for a division of the honours cannot be substantiated, even though Wulff was clearly unfortunate in that Bragg's paper was published in a journal which was probably not well known to him.

The translation has been carried out extremely competently, even if the English is inclined to be a little stilted in parts. The translators have added to the value of the book by including many extra references, and the author has contributed some recent Russian ones in his preface.

The book can be confidently recommended as an important work on the subject.

H. LIPSON

\section{RADIOACTIVE ISOTOPES}

Radioactive Isotopes

An Introduction to their Preparation, Measurement and Use. By W. J. Whitehouse and J. L. Putman. Pp. xvi $+424+5$ plates. (Oxford : Clarendon Press ; London: Oxford University Press, 1953.) 50s. net.

DRING the past decade the number of applications of radioactive isotopes has increased enormously, and the concomitant growth of interest has created a demand for appropriate text-books. For those who wish to read about the preparation of radioactive isotopes, their properties and uses, "Radioactive Isotopes" constitutes an excellent survey. The treatment is comprehensive and well balanced and the presentation generally lucid and precise : furthermore, the book arouses and maintains interest.

After a brief survey of the nuclear reactions which are used in the production of radioactive isotopes, the modes of nuclear disintegration are discussed together with the properties of the radiations. These topics occupy about a quarter of the book and they constitute the background for the remainder of the text. The authors then deal with the practical 